\title{
An Enhanced Analog Nearest Neighbor Algorithm for Route Planning After a Major Disaster
}

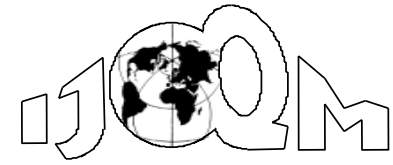

DOI: $10.46970 / 2020.26 .4 .1$

Volume 26, Number 4

December 2020, pp. 241-253

\author{
Romulo B. Magnaye \\ Ramapo College of New Jersey \\ (rmagnaye@ramapo.edu) \\ Brian J. Sauser \\ University of North Texas \\ (brian.sauser@unt.edu) \\ Sohail S. Chaudhry \\ Villanova University \\ (sohail.chaudhry@villanova.edu) \\ Thierry Rakotobe-Joel \\ Ramapo College of New Jersey \\ (trakotob@ramapo.edu)
}

As human-made and natural disasters become more severe, power and digitalcomputing capabilities become unavailable for longer periods of time in their aftermaths in villages across the developing countries. However, the need for village leaders and first-responders to promptly visit their residents, assess the damage and provide reassurances remain. They have to determine the shortest route which they have to take in order to visit all the residents and return to base to prepare their report for the town or provincial authorities and relief organizations. This paper describes a methodology for solving such a route planning problem without the need for digital computing power which is otherwise unavailable. The proposed approach is an enhanced version of the Nearest Neighbor Methodology algorithm used to solve the Traveling Salesman Problem. After the initial visit from the predetermined starting node (their home) is completed, the agent (village administrator or first-responder) chooses the succeeding destinations by determining the quickest way that the next 2 nearest neighbors can both be visited. This approach, called the Nearest Neighbor Methodology plus mini-tour, yields a shorter length for the tour when compared to the results from the Nearest Neighbor Methodology. It is, however, longer than the results produced by a computer-based genetic algorithm.

Keywords: Traveling Salesman Problem, Analog Route Planning, Genetic Algorithm, Disaster Assessment in Remote Locations

\section{Introduction}

This paper describes an analog methodology for solving a basic symmetric Traveling Salesman Problem (TSP). This approach can be used in situations where digital or electronic computing power is not available after a major natural or human-made disaster in a remote or underdeveloped part of the world. This specific application was conceptualized for use by the leader of the most basic political unit in the developing world whose responsibility is to cover around 10 hamlets or clusters of remotely located dwellings. The problem for the village leader (the "salesman") is to travel from 
her/his home to all remote locations (neighborhoods, hamlets) within her or his jurisdiction to assess the damage, provide basic relief in terms of goods/services, and/or establish an operational presence, albeit temporary. This routing problem can have a short-term temporal constraint in order to create the baseline data from which full-scale relief and recovery efforts can be planned. The first-responder must determine, without computing capability which is typically due to the loss of electric power, the shortest route to be taken to provide assistance as quickly as possible. In this paper, we illustrate how this problem can be tackled using the Nearest Neighbor Methodology (NNM) but enhanced by adding a mini tour after each remote location has been visited. This new methodology is termed as NNM with mini tours or $\mathrm{NNM}+\mathrm{m}$.

The need for such an approach is justified by the observation that human-made and natural disasters have become more frequent and severe such as a tsunami, cyclones, earthquakes, and mining accidents. During the $20^{\text {th }}$ century, occurrences of humanmade events have grown exponentially (Coleman 2006). In the $21^{\text {st }}$ century, 2.3 billion people have been directly impacted by natural disasters (Guha-Sapir et al. 2013). Kanti (2019) reported that since 2000, there have been more than 100 major natural and human-made disasters throughout the world. As the frequency and impact have increased, there is a need to determine how to assess and distribute resources and aid with greater efficiency under mobility, time, and other constraints.

The next sections of the paper describe a typical post-disaster scenario in a developing country, review the approaches which have been proposed and used to solve the TSP, present a sample problem, its solutions, and provide a comparative analysis with a discussion and a conclusion.

\section{A Post-Disaster Scenario}

This paper was motivated when one of the authors was asked a question by a leader of one of the most basic political units in the Philippines: how to bring a presence and as quickly as possible, assess needs of remotely located constituents after a major disaster has occurred. In the Philippines, this political unit is known as a "barangay" and the leader is responsible to provide assistance after the occurrence of the major disaster. As of 2019, there were 42,046 barangays with $82 \%$ classified as rural. Each rural barangay has about 10 clusters of homes ${ }^{1}$ connected to a barangay hall and to each other by dirt roads. Any public services offered are availed of by going to the barangay hall and not vice-versa. An elected leader holds office at the barangay hall. Rural electrification provided by the government usually stops at the barangay hall. It is also where any paved road connecting to the national road system terminates.

When a major tropical storm hits such a rural area, the roads, paved or otherwise, usually are washed away and this makes it hard for the head of the barangay to connect with her/his constituents in order to assess the damage and provide reassurance that help is on the way. As a result, it takes an alarmingly long time for any relief to arrive and when it does, it is not unusual for the wrong type of resources to be delivered to the residents. To address this, the concerned barangay leader would like to be able to assess first-hand the nature and extent of damage suffered by the constituents. After

${ }^{1}$ Each of these is called "purok" in the Philippines or "desa" in rural Indonesia. 
one such tropical storm, s/he sets out ${ }^{2}$ on her/his motorcycle ${ }^{3}$ and travels to each cluster of dwellings starting from her/his house to the nearest neighbor and so on until s/he has visited all the required clusters, reassured her/his residents, and made an assessment of what type of resources are required. After collecting the information from the constituents, the barangay leader returns to the starting point, prepares the report and proceeds to the town center. Eventually, the information is forwarded to the government's regional disaster coordinating council as well as to the private volunteer relief agencies.

Typically, this relief delivery process has been quite slow. During the meeting, the barangay captain wanted to know how he could speed up his side of the process. How could he assess the damage faster? The obvious answer to someone from a developed country would be to use cellular communications. However, this approach is not an option at the moment for the rural areas. Sturdy terrestrial or land-based systems which would survive the disasters such as storms would be prohibitively expensive.

In this paper, we address this question by trying to find a way to reduce the distance that the leader on her/his motorcycle must cover in order to conduct first-hand assessment of the type of aid needed by the constituents of the barangay.

\section{A Brief Review of Solutions to the Traveling Salesman Problem}

One of the most widely-studied Operations Management situations is the need to find an optimal path from a point of origin to several destinations that must be visited once before returning to the original point. This is commonly referred to as the Traveling Salesman Problem (TSP). TSP was first postulated in the 1920s by an Austrian mathematical economist, Karl Menger (Applegate et al. 2006). Practical situations where one encounters such applications are numerous including for planning sales or service calls, postal/parcel/package deliveries, diplomatic tours, manufacturing (drilling, welding, job sequencing, etc.), open-pit mining (equipment routing), and, as mentioned previously, damage assessment after a major disaster.

TSP is a complicated problem because the number of feasible solutions is large. They can range from a low of $0.5(\mathrm{~N}-1)$ ! for symmetric cases when distance or cost of travel is direction-neutral to $(\mathrm{N}-1)$ ! for non-symmetric problems ${ }^{4}$. Because of the complexity of this problem, very sophisticated heuristic algorithms have been proposed that are modeled after the study of natural phenomena such as those from Biology or Materials Science. Some of the biological systems that have been

\footnotetext{
${ }^{2}$ During our conversations with village managers in the Philippines, it was made clear to us that when there is an impending disaster, they will not stay in their village offices but would go home to ride the event out. Even if they do evacuate, their first move after surviving the disaster would be to go home first. Therefore, for this application, the starting and ending location will always be the village head's residence.

${ }^{3}$ In the absence of a motorcycle, a barangay leader, if so motivated, will do these inspections using a wooden sled pulled by a water buffalo or "carabao".

${ }^{4} \mathrm{~N}$ equals the number of cities in the problem. From the point of origin, the number of possible cities to visit is $(\mathrm{N}-1)$; it is $(\mathrm{N}-2)$ from the second city, $(\mathrm{N}-3)$ from the third and so on. For symmetrical systems where either direction between two cities is the same, we need to consider only half of these solutions.
} 
considered are based on the natural selection, Genetic Algorithm (Grefenstette et al. 1985), social networks and work organization, Ant Colony Optimization (Dorigo and Gambardella 1997), and Tabu Search (Glover 1989, Glover 1990, Gendreau et al. 1998). From Materials Science, pyro metallurgy and crystallography served as the basis for the Simulated Annealing Method (Skiscim and Golden 1983). Combinations of approaches have also been reported in the literature. For example, Genetic Algorithm has been combined with Ant Colony by Pilat and White (2002) to make the ACSGA algorithm. The advantage of using the hybrid methods is that with powerful computing systems, they can quickly generate solutions that are very close to the pareto-optimal solutions (up to within $2 \%$ for very large problems).

One of the earliest solutions was reported by Dantzig et al. (1954) when they tackled a problem with 49 cities or nodes in the network. Rosenkratz et al. (1977) analyzed several methodologies, later updated by Junger et al. (1995) and Larranaga et al. (1999). These are excellent self-contained introductions to the algorithms and computational aspects of the problem. Matai et al. (2010) is a more recent review of this work which is very accessible as it is published on-line. Rego et al. (2011) provided a comprehensive review focused on Ejection Chain Methods, more specifically the Lin-Kernighan and Stem-and-Cycle methods (Glover 1992; Glover 1996).

Most of this literature deals with a single salesman visiting each node within an area of interest once and the effort to do so, usually measured by distance, is symmetrical, i.e., the distance is the same going forwards or backwards. Gutin and Punnen (2002) presented variations to the basic TSP such as having multiple salesmen, referred to as the mTSP (Bektas 2006; Lo et al. 2018) and the asymmetric situation, ATSP (Ascheuer et al. 2000).

What this body of literature shows is that TSP is a puzzle which can grow more complicated exponentially as the number of nodes are increased. It can be solved by heuristic methods which require sophisticated algorithms executed on computers to which the first-responders in our scenario do not have access in the immediate aftermath of a disaster.

In addition, there are several studies which have utilized heuristics that can solve these types of problems quickly (for example, Bentley 1992 and Rosenthal et al. 2012). Rosenthal et al. (2012) introduced network optimization problems and showed the application of this problem to disaster relief situations. An integer programming formulation was presented and provided their computational experience on small sized problems. On the other hand, five heuristics were developed and applied to relatively large sized randomly generated problems with relatively good performance. Bentley (1992) formed three groups, namely heuristics which grow fragments, those that grow tours, and those which are based on trees. Specifically, the three variations of heuristics that grow fragments are the Nearest Neighbor, Double-Ended Nearest Neighbor, and Multiple Fragment heuristics. Those that grow trees can be formulated based on two expansion or insertion rules, namely addition and expansion. Within each rule, there are three selection rules. These are Nearest Addition, Farthest Addition, and Random Addition. The third group are the heuristics based on trees, namely Minimum Spanning Tree, Christofides' Heuristic, and Fast Recursive Partitioning Heuristic.

Among these fast heuristics, the Nearest Neighbor Method (NNM) can be considered to be the easiest to operate. Its origins are difficult to establish. However, 
what we know is that around the time that Dantzig (1954) published his solution to TSP, Clark and Evans (1954) published a paper which included the concept of the Nearest Neighbor as an approach for analyzing patterns for spatial maps. Gavett (1965) came up with an approach which looked like NNM but instead of spatial distances, he used the shortest set-up time for various jobs in an operation to determine optimal job sequencing which was termed as the Next Best Rule. Bellmore and Nemhauser (1968) presented NNM as a tour building approach, along with tour-totour and tour elimination approaches. Bentley (1992) described the heuristic, including a pseudo code, in great detail.

NNM is a simplified approach which can be performed "by hand" (analog) for moderate-sized problems. However, this approach does have some drawbacks. NNM has been found to be very sensitive to the starting node and tends to yield results which were $24.2 \%$ longer than an optimal Hamiltonian solution ${ }^{5}$ (Junger et al. 1995).

\section{The Problem}

An example of the scenario of interest to this paper is the period immediately following the occurrence of the November 8, 2013 Typhoon Haiyan in the Philippines (Takagi and Esteban 2016). The devastation which occurred was unprecedented in its magnitude - severity and coverage. Village leaders ${ }^{6}$ had to make initial assessment of the damage and determine the immediate needs specific to each locality so that the information was readily available as soon as the town or provincial authorities took over the relief efforts.

Table 1 Inter-Neighborhood Distances

\begin{tabular}{|c|c|c|c|c|c|c|c|c|c|c|}
\hline Node & $\mathbf{1}$ & $\mathbf{2}$ & $\mathbf{3}$ & $\mathbf{4}$ & $\mathbf{5}$ & $\mathbf{6}$ & $\mathbf{7}$ & $\mathbf{8}$ & $\mathbf{9}$ & $\mathbf{1 0}$ \\
\hline $\mathbf{1}$ & 0 & 7.649 & 7.877 & 7.875 & 5.964 & 4.561 & 5.903 & 6.810 & 5.701 & 7.642 \\
\hline $\mathbf{2}$ & 7.649 & 0 & 2.617 & 6.768 & 5.547 & 4.111 & 3.106 & 2.484 & 3.606 & 4.159 \\
\hline $\mathbf{3}$ & 7.877 & 2.617 & 0 & 4.386 & 3.701 & 3.401 & 2 & 4.885 & 5.661 & 6.673 \\
\hline $\mathbf{4}$ & 7.875 & 6.768 & 4.386 & 0 & 2.025 & 4.215 & 4.005 & 8.501 & 8.730 & 10.308 \\
\hline $\mathbf{5}$ & 5.964 & 5.547 & 3.701 & 2.025 & 0 & 2.256 & 2.470 & 6.873 & 6.912 & 8.628 \\
\hline $\mathbf{6}$ & 4.561 & 4.111 & 3.401 & 4.215 & 2.256 & 0 & 1.404 & 4.838 & 4.701 & 6.512 \\
\hline $\mathbf{7}$ & 5.903 & 3.106 & 2 & 4.005 & 2.470 & 1.404 & 0 & 4.501 & 4.780 & 6.303 \\
\hline $\mathbf{8}$ & 6.810 & 2.484 & 4.885 & 8.501 & 6.873 & 4.838 & 4.501 & 0 & 1.404 & 1.825 \\
\hline $\mathbf{9}$ & 5.701 & 3.606 & 5.661 & 8.730 & 6.912 & 4.701 & 4.780 & 1.404 & 0 & 2.025 \\
\hline $\mathbf{1 0}$ & 7.642 & 4.159 & 6.673 & 10.308 & 8.628 & 6.512 & 6.303 & 1.825 & 2.025 & 0 \\
\hline
\end{tabular}

The village leader must perform this task at the earliest possible time without power and lack of access to digital technology platforms. The only way the village leaders were to make such an assessment was through physical visits to each neighborhood or

\footnotetext{
${ }^{5}$ A Hamiltonian cycle is one that visits every node exactly once and is successively built by adding only the nodes which have not been visited. The length of the cycle should be the shortest (minimization problem).

${ }^{6}$ A village is called "barangay" and is headed by an elected "barangay captain."
} 
"purok" within their jurisdiction. For one remote barangay, the distances between each neighborhood are shown in Table 1 . There are 10 interconnected neighborhoods, and the objective is to complete the tour in the shortest distance or length possible.

Additional assumptions are that the village captain can visit each neighborhood only once and the distances between each neighborhood are the same in both directions. S/he must start from a predetermined starting point ${ }^{7}$. After the last neighborhood has been visited, the village captain then goes back to node 1 to prepare the report for the town or regional authorities.

\section{Basic Solutions to the Problem}

To quickly solve the problem, the NNM approach was applied to produce a fast solution. It is also reasonable to consider that the village leader will instinctively come up with this idea ${ }^{8}$. Anticipating that the route will not be the best (Junger et al. 1995), we then applied a basic genetic algorithm to find an improved solution. We expected that there would be a substantive difference between the two routes produced with the first route to be greater than the second obtained from the genetic algorithm. Next, we applied NNM+m to see if the longest route could be reduced. Based on our analysis, it was found that the route from the genetic algorithm was the shortest followed by $\mathrm{NNM}+\mathrm{m}$, and then the route generated by utilizing the NNM methodology. The new approach being proposed results in an improvement over the one obtained from NNM.

\subsection{Application of NNM and Solution}

Using the shortest distance data from Table 1, the starting point for the tour is predetermined to be node 1 which is where the village captain resides. In effect, this eliminates the need for her/him to be concerned as to where the best starting point should be (one of the drawbacks to NNM mentioned previously). From node 1, the manager proceeds to the nearest neighbor (node 6) and on to the nearest neighbor to node 6 which has not been visited yet, until all nodes have been visited once. The resulting route from this baseline procedure had a length of 35.023 units and utilizes the following sequence of nodes: 1-6-7-3-2-8-9-10-5-4-1.

\subsection{Application of Genetic Algorithm and Solution}

Again, using node 1 as a predetermined starting point, we applied a basic Genetic Algorithm (GA) using the following algorithm:

// C++ implementation of the above approach

\#include $\langle$ bits/stdc++.h>

\#include <limits.h>

Using namespace std;

// Number of cities in TSP

\#define $V 10$

\footnotetext{
${ }^{7}$ Village captains indicated that their starting point will be their homes. When they have to evacuate, their first destination when the disaster has passed will always be their own homes.

8 This was confirmed by our discussions with emergency managers and their staff in the Philippines.
} 
// Names of the cities

\#define GENES ABCDEFGHIJ

// Starting Node Value

\#define START 0

// Initial population size for the algorithm

\#define POP_SIZE 10

// Structure of a GNOME

// string defines the path traversed

// by the salesman while the fitness value

// of the path is stored in an integer

struct individual \{

string gnome;

float fitness; \};

The GA approach generated a route that was 29.678 units long which was about $15.26 \%$ shorter in length over the base route obtained using the baseline procedure. The sequence of nodes are as follows: 1-9-10-8-2-3-4-5-7-6-1.

\subsection{Application of NNM+m and Solution}

In order to reduce the length of the NNM route, the algorithm can take a more deliberate approach after the first nearest node from node 1 has been visited. That is, instead of going to the obvious next nearest neighbor, the emergency manager may look at the next two nearest neighbors, say nodes 5 and 7 . This now gives her/him two alternative segments to reach both nodes. S/he can calculate the length of each segment and then select the shortest route. In the above example, segment 6-5-7 was 4.726 units long while segment 6-7-5 was 3.874 units. Since the latter is shorter, the emergency manager proceeds to node 7 and then to node 5. This is what we call the Nearest Neighbor Method plus mini-tour or $\mathrm{NNM}+\mathrm{m}$. The pseudo code for $\mathrm{NNM}+\mathrm{m}$ is as follows:

- Calculate the distances between every pair of nodes.

- From the node of origin, proceed to the nearest node.

- From the last node visited, identify its two nearest neighbors.

- Calculate the length of a mini-tour to visit both nodes, choose the shorter one.

- $\quad$ Repeat the last 2 steps until all nodes have been visited.

- Return to the node of origin.

The steps of applying the $\mathrm{NNM}+\mathrm{m}$ approach to the distances between each neighborhood associated with Table 1 are listed in Table 2 . The generated route was 16-7-5-4-3-2-8-9-10-1 (indicated in bold and italics) with a total length of 31.018 units. This route was $11.44 \%$ shorter than the route obtained using the NNM approach. 
Table 2 Solution for the Nearest Neighbor Method + Mini-Tour

\begin{tabular}{|c|c|c|c|c|}
\hline Solution Steps & \begin{tabular}{|c|} 
City \\
$\#$ \\
\end{tabular} & \begin{tabular}{|l|} 
Mini- \\
Tour \\
\end{tabular} & $\begin{array}{c}\text { Length of two } \\
\text { mini-tours }\end{array}$ & \begin{tabular}{|c|}
$\begin{array}{c}\text { Length of shorter } \\
\text { mini-tour }\end{array}$ \\
\end{tabular} \\
\hline Select Starting city (1) & $\mathbf{1}$ & & & \\
\hline Proceed to nearest city (6) & 6 & & 4.561 & 4.561 \\
\hline Select 2 nearest cities & \begin{tabular}{|c|}
5 and \\
7
\end{tabular} & & & \\
\hline \multirow{2}{*}{$\begin{array}{l}\text { Plan mini-tours \& select shortest mini- } \\
\text { tour }\end{array}$} & & $6-5-7$ & $2.256+2.470$ & \\
\hline & & $6-7-5$ & $1.404+2.470$ & 3.874 \\
\hline \multirow{2}{*}{$\begin{array}{l}\text { From last city in previous tour (5), } \\
\text { select } 2 \text { nearest cities not yet visited \& } \\
\text { select shortest mini-tour }\end{array}$} & \multirow{2}{*}{$\begin{array}{c}3 \text { and } \\
4\end{array}$} & $5-3-4$ & $3.701+4.386$ & \\
\hline & & $5-4-3$ & $2.025+4.386$ & 6.411 \\
\hline \multirow{2}{*}{$\begin{array}{l}\text { From last city in previous tour ( } 3) \text {, } \\
\text { select } 2 \text { nearest cities not yet visited \& } \\
\text { select shortest mini-tour }\end{array}$} & \multirow{2}{*}{$\begin{array}{c}2 \text { and } \\
8\end{array}$} & $3-8-2$ & $8.501+2.484$ & \\
\hline & & $3-2-8$ & $6.768+2.484$ & 5.101 \\
\hline \multirow{2}{*}{$\begin{array}{l}\text { From last city in previous tour ( } 8) \text {, } \\
\text { select } 2 \text { nearest cities not yet visited \& } \\
\text { select shortest mini-tour }\end{array}$} & \multirow{2}{*}{$\begin{array}{c}9 \text { and } \\
10\end{array}$} & $8-9-10$ & $1.404+2.025$ & 3.429 \\
\hline & & $8-10-9$ & $1.825+2.025$ & \\
\hline \multirow{2}{*}{$\begin{array}{l}\text { If all cities have been visited, return to } \\
\text { the starting city to complete the tour }\end{array}$} & & $10-1$ & & 7.642 \\
\hline & & & & \\
\hline \multicolumn{2}{|l|}{ Calculate the length of the tour } & & & 31.018 \\
\hline
\end{tabular}

\subsection{Variations to $\mathrm{NNM}+\mathrm{m}$}

One variation to the NNM+m as formulated above was to start with the mini-tour immediately from the starting point, node 1 . That is, instead of going to node 6 which is the nearest neighbor to the manager right away, the mini-tour can already be performed by calculating the lengths of getting to the two nearest neighbors, nodes 6 and 9. The shorter route was from 1 to 6 to 9 . From node 9, the tour can repeat the process as many times necessary to reach all other nodes and then go home to node 1 . This modification provided a route which was 35.357 units in length. This was slightly longer in length and hence, this route may not be a viable option for the village leader.

Another variation was to increase the number of nodes considered in the mini-tour from 2 to 3 . However, the number of possible combinations of nodes increases significantly from 2 routes to consider in the 2-city mini-tour to 6 routes in the 3-city mini-tour. This was deemed to be too confusing and time consuming - practical complications which should be avoided in an emergency. 


\section{Discussion and Managerial Implications}

The results of the three methodologies are summarized in Table 3. The NNM route is the longest at 35.023 units. NNM+m yields a reduction in length of $11.44 \%$ at 31.018 units. The GA approach produced a solution which was $15.26 \%$ shorter than the one from NNM.

Table 3 Summary of the Routes and Route Distances of the Three Methods

\begin{tabular}{|c|c|c|}
\hline Method & Route & Route Distance \\
\hline Genetic Algorithm Route & $1-9-10-8-2-3-4-5-7-6-1$ & 29.678 \\
\hline Nearest Neighbor Methodology + Mini-Tour Route & $1-6-7-5-4-3-2-8-9-10-1$ & 31.018 \\
\hline Nearest Neighbor Route & $1-6-7-3-2-8-9-10-5-4-1$ & 35.023 \\
\hline
\end{tabular}

When the results were discussed with village captains in the Philippines ${ }^{9}$, the initial reaction was that the $11.44 \%$ reduction in the length of the tour provided by $N N M+m$ may not be that significant. The reason provided was that the time saved by having a shorter route may be equal to the time they would have to spend planning the route so why not just take off immediately after the disaster? However, after several practices and the method became more familiar to them and they established trust in the methodology, the entire route may no longer have to be predetermined before they can get going. They can take off immediately after the calamity has passed and just keep doing the 2-node mini-tour until all nodes have been visited once and they go back to their homes to prepare their initial assessments. The $11.44 \%$ reduction may also be more significant in practical terms towards the end of the tour when the village captains begin to feel exhaustion after going through some difficult terrain. This would be more likely in the aftermath of a disaster.

Results from the genetic algorithm showed a significant improvement over NNM and $\mathrm{NNM}+\mathrm{m}$ so should emergency management units just have these routes already determined as part of their arsenal of tools? Yes, if the impact of the disaster could also be pre-determined. However, such an ideal situation is unrealistic so $\mathrm{NNM}+\mathrm{m}$ provides a reasonable and a more practical solution.

In addition to first-response-to-disaster situations, there are other situations where an analog approach to determining a shorter route would be relevant. One may be where a one-person private contractor works with a major logistics and distribution outfit to deliver packages during the "last-mile" portion of order fulfillment which is the most expensive segment today (Gevaers et al. 2014, Zhang et al. 2019). The packages destined for residents in a neighborhood or hamlet are delivered to the residence of the private contractor who will then bring the items to the homes or offices of the recipients. On any given day, there will be a different set of recipients to whom the packages must be delivered so a simple, easy to follow system of local delivery will be very practical to the local contractor.

A possible extension of the NNM+m methodology would be to replace distance with population density. That is, the location's "nearness" would be determined by the number of residents in the various destinations which have to be visited. The most

\footnotetext{
${ }^{9}$ We acknowledge the inputs from the village captains in the city of Naga, Philippines.
} 
populated location will be visited first and the mini-tours that follow will be based on the population of each of the locations.

Refinements to the model can be made by relaxing the restriction on the starting point of the route. In more developed countries, for example, the leaders of local governments may stay home or at a command post so their starting point may vary. The jurisdictions may also be greater than just 10 locations. It is also possible that more "salesmen" may be involved to include additional emergency personnel who can assist the local leader such that multiple agents can fan-out to conduct the assessment faster. We intend to pursue these refinements but only if local managers confirm their desire for such models.

\section{Conclusion}

Human-made and natural disasters have become more frequent and severe in the $21^{\text {st }}$ century. As their severity have increased, during the aftermath, the failure of modern power and communication technologies has become more prolonged. However, there remains the need for a rapid efficient assessment of the damage which has occurred in order to map-out relief efforts more effectively. On-site inspections by the head of the most basic government unit are a must since residents cannot report the damage themselves. Another benefit from such presence is that it will reassure the residents that help is on its way. In these situations, village leaders must start promptly and complete their visits using the shortest route for the entire tour. That way, the assessment can be presented to relief organizations when they arrive and a coordinated plan that is both efficient and effective is drawn and implemented.

In such a situation, the simple Nearest Neighbor Methodology is what a logical village leader would use since it can be applied without the need for digital computing power. This paper suggested an enhanced version of this method by including a minitour after each step in its algorithm. Based on a real-world application, the similarly analog approach provided a tour which was shorter by $11.44 \%$. For comparison purposes, an improved solution to the example case was calculated using a computerbased genetic algorithm which obtained a $15.26 \%$ improvement. However, since computing power is not available during the aftermath of the disaster, the application of the NNM+m approach will provide a realistic route determination for the village captain to assess the disaster needs of the constituents.

There are possibly some enhancements which can be made to improve the results and bring them closer to the outcome from the genetic algorithm. However, such enhancement will require more complicated mathematical procedures for which a village captain may not have the time to perform if s/he were trying to get out the door promptly to assess and collect the requirements of the constituents in a timely manner for the government officials.

\section{References}

1. Applegate, D.L., Bixby, R.E., Chvátal, V., and Cook, W.J. (2007), the Traveling Salesman Problem: A Computational Study, New Jersey: Princeton University Press.

2. Ascheuer, N., Jünger, M., and Reinelt, G.A. (2000), “A branch and cut algorithm for the asymmetric traveling salesman problem with precedence constraints", Computational Optimization \& Applications, Vol. 17(No. 1), pp. 61-84. 
3. Bektas, T. (2006), "The multiple traveling salesman problem: an overview of formulations and solution procedures", Omega, Vol. 34(No. 3), pp. 209-219.

4. Bellmore, M., and Nemhauser, G.L. (1968), "The traveling salesman problem: a survey", Operations Research, Vol. 16(No. 3), pp. 538-558.

5. Bentley, J.J. (1992), "Fast algorithms for geometric traveling salesman problems", ORSA Journal on Computing, Vol. 4(No. 4), pp. 387-412.

6. Clark, P.J., and Evans. F.C. (1954), "Distance to nearest neighbor as a measure of spatial relationships in populations", Ecology, Vol. 35(No. 4), pp. 445-453.

7. Coleman, L. (2006), "Frequency of man-made disasters in the $20^{\text {th }}$ century", Journal of Contingencies and Crisis Management, Vol. 14(No. 1), pp. 3-11.

8. Dantzig, G., Fulkerson, R., and Johnson, S. (1954), "Solution of a large-scale traveling-salesman problem", Journal of the Operations Research Society of America, Vol. 2(No. 4), pp. 393-410.

9. Dorigo, M., and Gambardella, L.M. (1997), "Ant colonies for the travelling salesman problem", Biosystems, Vol. 43(No. 2), pp. 73-81.

10. Gavett, J.W. (1965), "Three heuristics rules for sequencing jobs to a single production facility", Management Science, Vol. 11(No. 8), pp. 166-176.

11. Gendreau, M., Hertz, A., and Laporte, G. (1994), "A tabu search heuristic for the vehicle routing problem”, Management Science, Vol. 40(No. 10), pp. 1276-1290.

12. Gevaers, R., de Voorde, E.V., and Vane slander, T. (2014), "Cost modeling and simulation of last-mile characteristics in an innovative B2C supply chain environment with implications on urban areas and cities", Procedia - Social and Behavioral Sciences, Vol. 125, pp. 398-411.

13. Glover, F. (1989), "Tabu search - part I", ORSA Journal on Computing, Vol. 1(No. 3), pp. 190-206.

14. Glover, F. (1990), “Tabu search - part II", ORSA Journal on Computing, Vol. 2(No. 1), pp. 4-32.

15. Glover, F. (1992), "New ejection chains and alternating path methods for traveling salesman problems”. In: Balci, O., Sharda, R., and Zenios, S. (Eds), Computer Science and Operations Research: New Developments in their Interfaces, pp. 491-509, Amsterdam: Pergamon Press.

16. Glover, F. (1996), "Ejection chains, reference structures and alternating path methods for traveling salesman problems", Discrete Applied Mathematics, Vol. 65(No. 1-3), pp. 223-253.

17. Grefenstette, J.J., Gopal, R., Rosmaita, B.J., and Gucht, D.V. (1985), "Genetic algorithms for the traveling salesman problem”. In: Grefenstette, J.J. (Ed.), Proceedings of the First International Conference on Genetic Algorithms and Their Applications, pp.160-168, Hillsdale, NJ: Lawrence Erlbaum Associates.

18. Guha-Sapir, D., D’Aoust, D., Vos, F., and Hoyois, P. (2013), "The frequency and impact of natural disasters". In: Guha-Sapir, D. and Santos, I. (Eds.), the Economic Impact of Natural Disasters, Oxford University Press, pp. 7-28.

19. Gutin, G., and Punnen, A.P. (Eds.) (2002), Traveling Salesman Problem and its Variations, Boston/Dordrecht/London: Kluwer Academic Publishers.

20. Jünger, M., Reinelt, G., and Rinaldi, G. (1995), "The traveling salesman problem”. In: Handbooks in Operations Research and Management Science, Vol. 7, Network Models, Ball, M.O., Magnanti, T.L., Monma, C.L., and Nemhauser, G.L. (Eds.), Chapter 4, pp. 225-330. Amsterdam: Elsevier Science B.V. 
21. Larrañaga, P., Kuijpers, C.M.H., Murga, R.H., Inza, I., and Dizdarevic, S., (1999), "Genetic algorithm for the traveling salesman problem: a review of representations and operators", Artificial Intelligence Review, Vol. 13(No. 2), pp. 129-170.

22. Lo, K-M., Yi, W-Y., Wong, P-K., Leung, K-S., Leung, Y., and Mak, S-T. (2018), "A genetic algorithm with new local operators for multiple traveling salesman problems", International Journal of Computational Intelligence Systems, Vol. 11(No. 1), pp. 692-705.

23. Matai, R., Singh, S.P., and Mittal, M.L. (2010), "Traveling salesman problem: an overview of applications, formulations and solution approaches". In: Prof. D. Davendra (Ed.), Traveling Salesman Problem, Theory and Applications, pp. 1-24, Rijeka, Croatia: In Tech Europe. Available from:

http://www.intechopen.com/books/traveling-salesman-problem-theory-andapplications/traveling-salesman-problem-an-overview-of-applicationsformulations-and-solution-approaches

24. Paul, B.K. (2019), "Response to and emergency relief efforts for the selected disasters". In: Disaster Relief Aid: Changes and Challenges, Palgrave Macmillan, pp. 141-194.

25. Pilat, M.L., and White, T., (2002), "Using genetic algorithms to optimize ACSTSP". In: Dorigo, M., Dicaro, G., and Samples, M., (Eds): Ant Algorithms, ANTS 2002, Lecture Notes in Computer Science, Vol. 2463, pp. 282-287.

26. Rego, C., Gamboa, D., Glover, F., and Osterman, C. (2011), "Traveling salesman problem heuristics: leading methods, implementations and latest advances", European Journal of Operational Research, Vol. 211(No. 3), pp. 427-441.

27. Rosenkrantz, D.J., Stearns, R.E., and Lewis, P.M. (1977), “An analysis of several heuristics for the traveling salesman problem", SIAM Journal of Computing, Vol. 6(No. 3), pp. 563-581.

28. Rosenthal, E.C., Chaudhry, S.S., Choi, I-C., and Jang, J. (2012), "On a class of branching problems in broadcasting and distribution", Computers and Operations Research, Vol. 39(No. 8), pp. 1793-1799.

29. Skiscim, C.C., and Golden, B.L. (1983), "Optimization by simulated annealing: a preliminary computational study for the TSP". In: Roberts, S., Banks, J., and Schmeiser, B. (Eds), Proceedings of the $15^{\text {th }}$ Conference on Winter Simulation (WSC'83), Vol. 2, pp. 523-535, Arlington, Virginia: IEEE Press.

30. Takagi, H., and Esteban, M. (2016), "Statistics of tropical cyclone landfalls in the Philippines: unusual characteristics of 2013 typhoon Haiyan", Natural Hazards, Vol. 80(No. 1), pp. 211-222.

31. Zhang, Y., Sun, L., Hu, X., and Zhao, C. (2019), "Order consolidation for the lastmile split delivery in online retailing", Transportation Research Part E: Logistics and Transportation Review, Vol. 122, pp. 309-327.

\section{About Our Authors}

Romulo Babor Magnaye teaches at the Anisfield School of Business of Ramapo College and is a Visiting Scholar at the University of North Texas. He is a Robert Crooks Stanley Fellow and a British Council Fellow. He has taught at Stevens Institute of Technology, Penn State, Skidmore College, and Rensselaer Polytechnic Institute. 
Before joining the academe, he worked in the Philippines for Philex Mining Corporation, the National Development Company, and in the Office of the Secretary of Natural Resources. He has a B.S. (Mining Engineering) and MBA from the University of the Philippines, a Postgraduate Diploma from Camborne School of Mines, and a Ph.D. from Stevens Institute of Technology. He is a registered Professional Mining Engineer.

Brian Sauser is a Professor at the University of North Texas in the G. Brint Ryan College of Business. He serves as the Director of the Complex Logistics Systems Laboratory, Program Coordinator of the Logistics Systems PhD Program, and Degree Architect of the BS in Industrial Distribution. He is a NASA Faculty Fellow, UNT Faculty Leadership Fellow, Professional Development Institute Business Fellow, IEEE Senior Member, and Associate Editor of the IEEE Systems Journal. He holds a B.S. from Texas A\&M University, M.S. from Rutgers, The State University of New Jersey, and Ph.D. from Stevens Institute of Technology.

Sohail S. Chaudhry is a Professor in the Department of Management and Operations at Villanova School of Business. He received his B.Sc. in Mechanical Engineering from Mosul University, Iraq, and his M.S. and Ph.D. in Industrial Engineering and Operations Research from Columbia University. His research and teaching interests are in the areas of Operations and Supply Chain Management and Information Systems. He serves as a member on the Editorial Advisory Boards of several international journals and as an Associate Editor of Enterprise Information Systems and Journal of Industrial Integration and Management. Previously, he has taught at Columbia University, Loyola University Chicago, Mosul University, and University of Wisconsin at La Crosse.

Thierry Rakotobe-Joel is an Associate Professor of Management at Ramapo College of New Jersey. He has his Ph.D from the University of Cincinnati. His research interest is in the area of operations strategy and sustainability ethics. He was a Fulbright scholar and research fellow at the University of Warwick and the University of Sheffield in the UK. His articles have appeared in Computational and Mathematical Organization Theory, Benchmarking, Quality Engineering, and the International Journal of Manufacturing Technology and Management. He is a member of the Academy of Management, the Institute for Operations Research and the Management Sciences, and the Production and Operations Management Society. 